\title{
Fraccionamientos cerrados residenciales, productores de inseguridad urbana subjetiva*
}

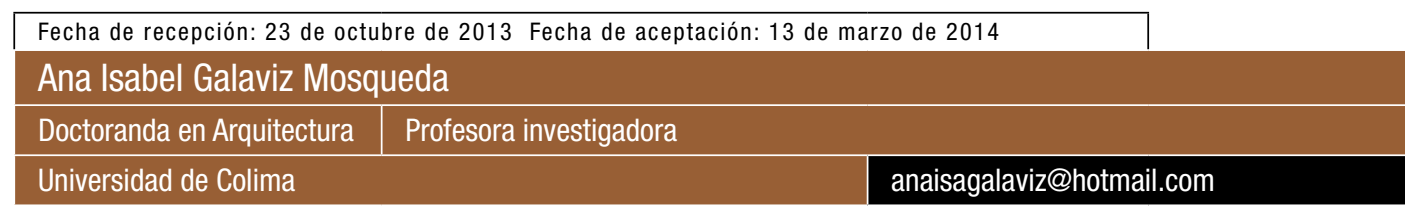

Reyna Valladares Anguiano

Doctora en Arquitectura $\quad$ Profesora investigadora

Universidad de Colima

reyna_v_a@yahoo.com.mx

\section{Martha Chávez}

Doctora en Arquitectura

Universidad de Colima

Resumen Independientemente del tamaño, de la importancia o las particularidades de las ciudades y sus sociedades, las condiciones de aislamiento y encerramiento sociourbano de los fraccionamientos cerrados residenciales de clase alta enfatizan aspectos subjetivos de inseguridad urbana como percepción de riesgo, imaginarios del miedo y sentimientos de inseguridad. Con método descriptivo-correlacional o estrategia no experimental mixta, este estudio muestra el impacto de lo mencionado en la vida cotidiana de sus habitantes. Este hecho acentúa dicotomías sociourbanas que incrementan el miedo al otro diferente y al territorio desconocido, modifica significados tradicionales atribuidos al concepto de inseguridad urbana, supera procesos formales de seguridad y traspasa fronteras, jerarquías de ciudad y tipologías de sociedades. Todo esto afecta las estructuras psicosociales de sus residentes, abona la cultura del miedo, consolida una espiral ascendente de inseguridad urbana, imprime universalidad en la relación entre aspectos subjetivos de inseguridad urbana y la manera en que se vive, conforma el territorio y estructura el espacio urbano.

Palabras clave Inseguridad urbana subjetiva; fraccionamientos cerrados

Palabras clave Inseguridad (Problema social); vecindario descriptor 


\section{Closed Residential Developments, Producers of Subjective Urban Insecurity}

Abstract Regardless of size, the importance or the particularities of cities and societies, the conditions of isolation and confinement of socio-urban residential gated high-class developments emphasize subjective aspects of urban insecurity as risk perception, fear stereotypes and feelings of insecurity. With the descriptive correlational method or mixed non-experimental strategy, this study shows the impact of the above-mentioned issues in the daily lives of its inhabitants. This fact emphasizes socio-urban dichotomies that increase the fear of the one who is different and of the unfamiliar territory, it modifies traditional meanings attributed to the concept of urban insecurity, it surpasses formal security processes and crosses boundaries, city hierarchies and typologies of societies. All this affects the psychosocial structures of its residents, contributes to the culture of fear, strengthens ascending urban insecurity spiral, gives universality in the relationship between subjective aspects of urban insecurity and the way we live, forms the territory and structures urban spaces.

Key words Urban insecurity opinion; closed residential developments

Key words Insecurity (Social problem); neighborhood

plus

\section{Loteamentos fechados residenciais, produtores de insegurança urbana subjetiva}

Resumo Independentemente do comprimento, da importância ou as particularidades das cidades e suas sociedades, as condições de isolamento e fechamento sociourbano dos loteamentos fechados residenciais de classe alta enfatizam aspectos subjetivos de insegurança urbana tais como percepção de risco, imaginários do medo e sentimentos de insegurança. Com método descritivo-correlacional ou estratégia não experimental mista, este estúdio mostra o impacto do mencionado na vida quotidiana dos seus habitantes. Este feito remarca dicotomias sociourbanas que incrementam o medo ao outro diferente e ao território desconhecido, modifica significados tradicionais atribuídos ao conceito de insegurança urbana, supera processos formais de segurança e transpassa fronteiras, hierarquias de cidade e tipologias de sociedades. Todo isso afeta as estruturas psicossociais dos residentes, abona a cultura do medo, consolida uma espiral ascendente de insegurança urbana, imprime universalidade na relação entre aspectos subjetivos de insegurança urbana e a maneira em que se vive, conforma o território e estrutura o espaço urbano.

Palavras chave Insegurança urbana subjetiva; loteamentos fechados

Palavras chave Insegurança (problema social); vizinhança descritor 


\section{Introducción}

Pese a que la inseguridad es un problema añejo en la historia de nuestras sociedades, la problemática se ha generalizado y complejizado cada vez más, al presentarse en la vida cotidiana de los moradores de las urbes. Asimismo, sus efectos han superado los significados tradicionales y los elementos objetivos atribuidos al concepto de inseguridad y han traspasado fronteras, jerarquías, tipologías, particularidades y tamaños de estas ciudades.

Se hace necesario volcar la mirada hacia los elementos subjetivos presentes en el fenómeno, que nos permitan comprender las múltiples dimensiones, los rasgos y las caracterizaciones del problema, más allá de la realidad numérica de las estadísticas delincuenciales nacionales e internacionales y de los procesos de seguridad pública habituales con los que se ha tratado de resolver la inseguridad urbana.

Esto vuelve pertinente la incursión en el entendimiento de otras situaciones como la percepción de riesgo, los sentimientos de inseguridad y los imaginarios del miedo que, si bien son elementos subjetivos de la inseguridad urbana, para quienes los viven son reales, así como sus consecuencias y efectos. Aunque cada sociedad presenta condiciones locales específicas, en la globalización, estos múltiples escenarios invaden tanto a los habitantes de las metrópolis y grandes ciudades como a los de las medianas y pequeñas y conforman sociedades del miedo.

Ahora bien, para la República mexicana, las proyecciones poblacionales de la ONU-Hábitat y
Sedesol (2011) estiman que el país alcanzará los 121 millones de personas, quienes no podrán albergarse solo en las megalópolis; así, se generará una movilidad poblacional a las ciudades intermedias o medias y enfrentarán retos complejos para definir políticas públicas adecuadas en materia de planeación urbana.

Ello hace pertinente que se cuente con información sustentada sobre las diversas aristas de la delincuencia en las ciudades intermedias o medias, que coadyuve a desarrollar respuestas urbanísticas más ajustadas a cada contexto para prever o disminuir impactos en sus sociedades. Lo anterior motivó el presente trabajo en Colima-Villa de Álvarez, ya que en el sistema urbano de ciudades (SUC) de 2011 es considerada como una de las ciudades medias mexicanas de mayor potencial socioeconómico por su emplazamiento geográfico y sus características intrínsecas que se enfrenta a los retos antes descritos (ONU-Hábitat y Sedesol, 2011).

Se estableció como premisa que los espacios urbanos, más allá de un simple territorio físico, son la materialización de símbolos y significados sociourbanos. Es la conjunción de los elementos biopsicosociales de los individuos en una colectividad lo que retroalimenta a estos lugares y es el propio sitio el que produce percepciones, sentimientos e imaginarios (Rapoport, 1978; Vuanello, 2006; Bauman, 2007; Beltrao, 2007; Hiernaux, 2007; Silva, 2008).

Por lo tanto, los espacios urbanos se convierten en un código de comunicación no verbal que 
estimula sensaciones en un $77 \%$ de los mexicanos que viven en un ambiente urbano (Salingaros, 2005, p. 75) y que, de acuerdo con las características de estos ambientes, sus residentes pueden vivirlos, habitarlos, recorrerlos o, por el contrario, se sienten limitados, confinados, fragmentados o aislados, lo que trae efectos que inciden en las prácticas urbanas y que se hacen visibles en las nuevas formas de producción del espacio urbano que reestructuran el territorio.

Consideramos, entonces, que los fraccionamientos cerrados residenciales, entendidos como la expresión territorial de la privatización del espacio, del encerramiento y aislamiento sociourbano y adoptados como un "estilo de vida globalizado" (Ciccolella y Mignaqui, 2008, p. 48) tienen relación directa con los elementos subjetivos de la inseguridad urbana.

En este texto se demuestra que las condiciones de encerramiento y aislamiento sociourbano generadas por los fraccionamientos cerrados residenciales de clase alta de la ciudad conurbada Colima-Villa de Álvarez influyen en la percepción de riesgo de los moradores del interior, por lo que modifican sus rutinas y prácticas urbanas y se fortalece una espiral ascendente de inseguridad urbana.

Este artículo se basa en un trabajo no experimental de tipo descriptivo correlacional, con estrategia mixta, de muestreo probabilístico por medio de encuestas, entrevistas, mapas mentales y fichas de campo. Se comprobó que la idea de la inseguridad urbana se incrementa en las condiciones de encerramiento y aislamiento sociourbano, propiciadas por los fraccionamientos cerrados. Para esto, se llevó a cabo una comparación de la percepción de riesgo, los sentimientos de inseguridad y los imaginarios del miedo de residentes del mismo grupo y estatus socioeconómico, tiempo de residencia, origen y rango de edad que habitan en contextos diferentes: al interior de los fraccionamientos cerrados residenciales de clase alta (grupo A) y al interior de fraccionamientos abiertos residenciales de clase alta (grupo B).

\section{La ciudad del siglo XXI: globalización, fraccionamientos cerrados residenciales e inseguridad urbana}

El siglo XXI ha sido testigo de las transformaciones de las metrópolis latinoamericanas en escenarios principales de los efectos de la globalización, que se han diseminado a todas las jerarquías de ciudad y estructuras de sus sociedades, ha llevado a los Gobiernos locales a asumir retos y costos que no han podido asimilar y controlar, como:

[La] incertidumbre, la imprevisibilidad de los cambios, dificultades en prefigurar escenarios de desarrollo a largo plazo, complejidad creciente de las dinámicas y problemáticas urbanas, selectividad del capital inmobiliario en sus estrategias de localización territorial e inversores y desarrolladores actuando en un mercado global de bienes raíces (Ciccolella y Mignaqui, 2008, p. 48).

Los fraccionamientos cerrados residenciales de clase alta se han ofertado como un producto mercadológico, dotado de cualidades espaciales como exclusividad, seguridad, calidad de vida y naturaleza (Giglia, 2003; Cáceres y Sabatini, 2004). Con esto se difunde la creencia de que con el encerramiento y aislamiento sociourbano de los fraccionamientos residenciales de clase alta se protege a sus residentes de una ciudad caótica e insegura per se, como una regla general e ignora las particularidades locales de las ciudades medias o pequeñas.

Desde esta lógica, el hecho de vivir en un área espacial definida, delimitada con barreras físicas de cerramiento espacial, ordenada y controlada 
(Marcuse, 2001; Valenzuela, 2007) trae implícita la concepción de la ciudad como un espacio caótico, inestable, descontrolado e inseguro del que es necesario autoexcluirse como alternativa de autoprotección, en donde la seguridad urbana se convierte en un bien adquirible o negociable a manera de privilegio individual, que marca separaciones socioespaciales y crea dicotomías sociourbanas como el adentro/afuera, lo privado/ público, la seguridad/inseguridad, el orden/desorden y confina grupos socialmente homogéneos al interior, separados de sus iguales del exterior, que simbolizan y significan un nosotros/otros.

Estas nuevas relaciones, rutinas, prácticas y comportamientos modifican la significación del concepto formal de inseguridad urbana y hacen visible la necesidad de integrar variables como la percepción del riesgo y los imaginarios del miedo, ya que, como afirma Robert King Merton (1994), según el teorema de Thomas, "las situaciones que el individuo define como reales, son reales en sus consecuencias" (Merton, 1994, p. 78).

\section{Percepción de riesgo, sentimientos de inseguridad e imaginarios del miedo}

Aunque las corrientes epistemológicas consideran que la percepción es de carácter inmediato y los idealistas afirman que es de carácter mediato, el presente trabajo retoma la teoría fenomenológica, debido a que utiliza conceptos tendientes a explicar los fenómenos o aspectos fenomenológicos de la realidad e implica que lo percibido tiene características físicas que lo definen y delimitan, condicionadas por un proceso racional que involucra juicios de valor aprendidos en una sociedad determinada y que lo visible es una idea que no necesariamente es cierta, sino que se asume así. La aprehensión de la realidad mediante los sentidos se sujeta a un proceso en el que los objetos se manifiestan como tales en un acto de experiencia que, al ser interpretada por la estimulación del medio, permite evocar objetos y hechos dotados de significación, con lo que captamos la realidad como algo organizado, estructurado y pleno de sentido y significado (Quintero, 2007, p. 198).

El espacio genera estímulos y sensaciones que la percepción del individuo traduce en imágenes mentales, procesadas cognoscitivamente para incorporarles ideales obtenidos de su estructura socioeconómica y cultural, que configuran un imaginario que será confrontado con su realidad para emitir un juicio (Hiernaux, 2007, pp. 25-79).

Cuando estas sensaciones están asociadas con imaginarios negativos, surge una sensación de desprotección.

En este caso, los espacios y elementos de encerramiento y aislamiento de estos fraccionamientos caracterizados por barreras que confinan a un conjunto de iguales en oposición de los otros diferentes estructuran escenarios que condicionan la percepción de sus habitantes para crear información sensitiva que es guardada en el cerebro como miedo y evocada en ciertos momentos como un imaginario que influencia su conformación psicológica y social y modela sentimientos de inseguridad que eventualmente serán de alcance cultural.

Ya sea por la necesidad del individuo de buscar los mecanismos para protegerse de los riesgos o del otro diferente, cualquiera que este sea; por la globalización de estos fraccionamientos como garantes de exclusividad, distinción, calidad de vida o seguridad; por la excesiva tendencia a generar imágenes más que reflexiones profundas o por las dificultades del Estado local para comprender las necesidades de su sociedad relativas a la seguridad urbana y de desarrollar formas eficaces 
de intervención sobre el espacio urbano, los individuos con la capacidad económica y la afinidad social para ello optan por los fraccionamientos cerrados residenciales de clase alta, aunque estos no hayan podido demostrar su eficacia. Por el contrario, sus elementos de cierre y aislamiento condicionan socioespacialmente al desconocimiento del otro, causan un estado de paranoia permanente que "incrementa las diferencias como si fuesen dos mundos: el del lenguaje de los riesgos cuantificables y el de la inseguridad no cuantificable que se está creando" (Beck, 2005, p. 45).

Cuando los índices delictivos y los ilícitos cometidos por sujetos que habitan en otras Naciones, ciudades, colonias o barrios permean el entorno de los residentes que viven en un interior de iguales contra un exterior del otro diferente (Paulsen, 2010, p. 150), se acentúa la concepción de la ciudad caótica, desordenada, desarticulada y, por tanto, riesgosa e insegura.

La ciudad imaginada precede a la real y la impulsa en su construcción (Bauman, 2007); por lo tanto, comprender el sentido de lo urbano para los fraccionamientos cerrados residenciales de clase alta requiere entender la lógica de un dentro-afuera, antes-después, los rizomas urbanos (Silva, 2004, p. 2) $)^{1}$ y el corto circuito de miradas que convierten al miedo en un elemento de la sociedad que se magnifica y se ha vuelto una motivación para actuar, pensar y sentir y marca de manera significativa la ruta en la producción del espacio.

Como lo afirma Armando Silva (2004), la ciudad es una proyección de sus habitantes y se construye en un ciclo imaginario-representación-sensación-percepción-sentimientos- acción-modificación del espacio-construcción de imágenes-imaginario. Si el imaginario de inicio es negativo — como el miedo- entonces puede comenzar un ciclo nocivo que, en tanto vaya consolidándose, formará una espiral ascendente en la cultura del miedo.

De acuerdo con la bibliografía revisada, la mayoría de los trabajos relativos a los fraccionamientos cerrados residenciales de clase alta se han concentrado en los aspectos objetivos de la inseguridad urbana contextualizados en las megalópolis o metrópolis; sin embargo, aunque las ciudades medianas o pequeñas presentan un número menor de delitos, complejidades diversas y problemáticas menos acentuadas (Chávez, 1996; Valladares, 2006; Maycotte, 2006; Juárez, 2006; Beltrao, 2007), en sus residentes son estadísticamente más significativos los sentimientos de inseguridad, por lo que el presente estudio se concentró en una ciudad media.

Algunos estudiosos como Sabatini (2008) y Cárdenas Munguía (2004) han detectado beneficios que el modelo de los fraccionamientos cerrados residenciales de clase alta aporta al ámbito individual y al colectivo. Para comprender las lógicas sociales que forman parte de la reproducción de este modelo (Sabatini, 2008, p. 23) es indispensable una mirada hacia los efectos que los aspectos negativos detectados generan en las estructuras psicosociourbanas.

\section{Caso de estudio}

Históricamente, la conurbación Colima-Villa de Álvarez se ha ubicado en las estadísticas delincuenciales por debajo de la media nacional; sin 
embargo, en la última década, en las estadísticas de percepción de inseguridad se ha posicionado entre los primeros cinco lugares de la media nacional ${ }^{2}$.

Liliana Juárez Martínez (2006) afirma que el discurso empleado por los moradores de los fraccionamientos cerrados residenciales estudiados era relativo a la adopción de la propuesta como un distintivo de exclusividad, pero sobre todo como "arma de protección contra los altos índices delictivos" (p. 98).

Esta contradicción evidencia que la inseguridad de los habitantes responde a variables subjetivas y que, en función de ello, se asume y desarrolla un modelo urbano-arquitectónico que no ha respondido a condiciones, particularidades locales o datos de la inseguridad objetiva (Vuanello, 2006, p. 26) ${ }^{3}$. De la conurbación y efectos adversos a la solución del problema de la inseguridad urbana de la ciudad conurbada Colima-Villa de Álvarez.

En las dimensiones urbana y psicosocial se integraron elementos y características socioeconómicas, sociodemográficas y urbano-arquitectónicas a los instrumentos de campo, que nos permitieron indagar sobre las particularidades físico-espaciales de los fraccionamientos cerrados y abiertos, la identificación de sus residentes con el entorno, las calificaciones urbanas que asignan a su fraccionamiento, sus rutinas y sus prácticas, para medir las variables referentes a la percepción de riesgo.

Como área de estudio, se identificó a la zona norte de la ciudad de Colima-Villa de Álvarez, ya que es la zona habitacional residencial de clase alta de la conurbación. Con criterios de selección definidos con base en el marco teórico, se identificaron cinco fraccionamientos cerrados residenciales o unidades de análisis, así como cinco fraccionamientos abiertos residenciales o unidades testigo, todos de clase alta (Figura 1).

En los instrumentos se incluyó un apartado de generalidades, integrado por ítems relativos a conocer algunas características del encuestado - su origen, el de sus padres, tiempo de residencia en la ciudad y en la vivienda actual, entre otrasque fueron contempladas en el análisis de resultados, pero que, por la extensión requerida para el presente documento, no se detallan gráficamente. Solo se muestran los datos obtenidos en los apartados de identificación, calificaciones urbanas, sentimientos y rutinas.

La teoría afirma que la condición de ser o no víctima del delito y su recurrencia influyen en la percepción de riesgo de una persona (Vuanello, 2008, p. 30). Por ello, se cuestionó a la población estudiada las veces que había sido víctima de algún delito.

Se identificó que un 59\% de los moradores estudiados en el interior de los fraccionamientos cerrados residenciales no había sido víctima del delito; sin embargo, un 56\% de ellos dijo sentirse muy intranquilo, vulnerable o inseguro si alguna persona que no es residente del fraccionamiento o que desconoce y que denomina como extraña lo aborda dentro de este; en contraste, de un $74 \%$ de los habitantes de los fraccionamientos abiertos residenciales de clase alta (residentes del exterior) que sí ha sido víctima del delito una o más veces, solo un $21 \%$ se siente muy inseguro ante la situación descrita (Figura 2).

2 Para más datos, ver las Encuestas Nacionales de Victimización y Percepción sobre Seguridad Pública (Envipe)

3 Desde el punto de vista de algunos criminólogos y psicólogos como Roxana Vuanello, la inseguridad urbana está compuesta por dos vertientes o campos de estudio: la primera es la inseguridad objetiva que es relativa al número de delitos producidos y el riesgo real que depende de los grupos vulnerables y de variables como edad, género, rutinas personales, vivienda, trabajo, pertenencia a una clase o sector social y constituyen el volumen estadístico de la delincuencia y sus consecuencias; la segunda es la inseguridad subjetiva, que es el temor al delito y genera una percepción de la delincuencia y del riesgo de ser victimizado. 
Figura 1.

Localización de las unidades de análisis

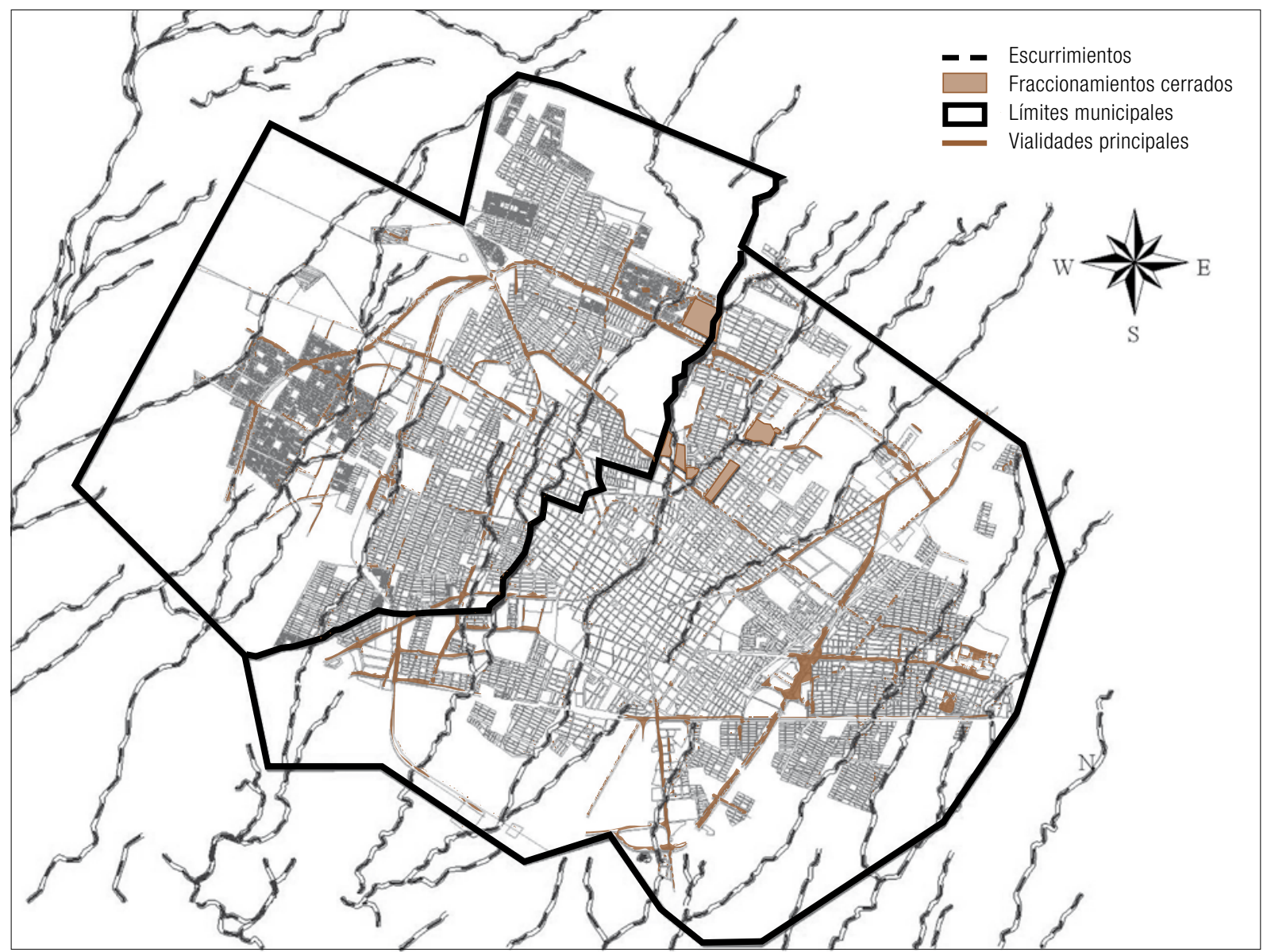

Fuente: elaboración propia

Figura 2.

Sentimientos de vulnerabilidad o inseguridad

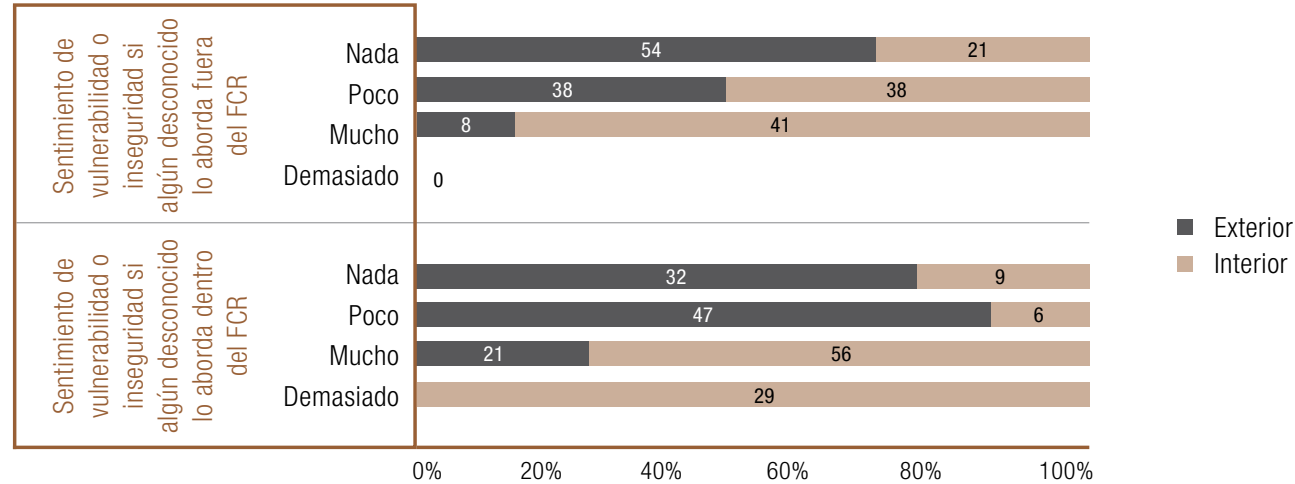


Debido a que los elementos de cierre de los fraccionamientos residenciales definen una nueva forma de vivir y experimentar el espacio urbano, fue necesario ahondar en la "articulación de las prácticas con la experiencia espacial y el espacio vivido" (Hiernaux, 2007, p. 17), ya que se pretendía identificar la manera en que estos elementos espaciales eran percibidos, experimentados y vividos por el individuo, el valor simbólico que les asignaban y los efectos que les generaban de acuerdo con la lectura que los moradores hacen de estos espacios, con la finalidad de conocer, mediante las imágenes, la preferencia de su uso en la rutina diaria.

Se desarrolló un apartado de las calificaciones urbanas otorgadas por los habitantes a diversos elementos de sus fraccionamientos. Se mostró al encuestado la acera "A", correspondiente a las banquetas de los fraccionamientos cerrados, la cual cuenta con arborización que produce sombra en la mayoría de los tramos y está franqueada con el prolongado muro perimetral del fraccionamiento cerrado; la acera "B", que corresponde a la banqueta contraria a la unidad de análisis, con dimensiones similares, menor arborización, con mixtura de usos y menor longitud de cuadras (Figura 3).
Los datos obtenidos mostraron que un $72 \%$ de los residentes del exterior prefieren la acera "B". Argumentan que al transitar a pie o en vehículo les reporta mayor comodidad, cercanía y tranquilidad: "Veo cosas diferentes y me distraigo" y "siento el camino menos largo". Los moradores del interior aclaran que nunca caminan en la calle, pero predomina en un $68 \%$ la predilección por la acera " $A$ ", ya que es la imagen que asocian con su contexto inmediato y la relacionan con su simbolismo de seguridad: "Veo la barda todos los días cuando salimos o llegamos y me hace sentir tranquilo; siento que ya estoy seguro, porque voy llegando a mi casa”.

Las calificaciones que los habitantes asignan a un espacio urbano están relacionadas con su percepción y sus imaginarios (Rapoport, 1971; Vuanello, 2006; Hiernaux, 2007; Silva, 2008), por lo que se indagó sobre las calificaciones respecto a la seguridad que otorgan a su entorno. Un 51\% de los residentes del interior consideró que a su fraccionamiento le faltaba seguridad, a diferencia de $65 \%$ de los moradores del exterior, que consideran a su fraccionamiento muy seguro (Figura 4).

Figura 3.

Avenida Constitución
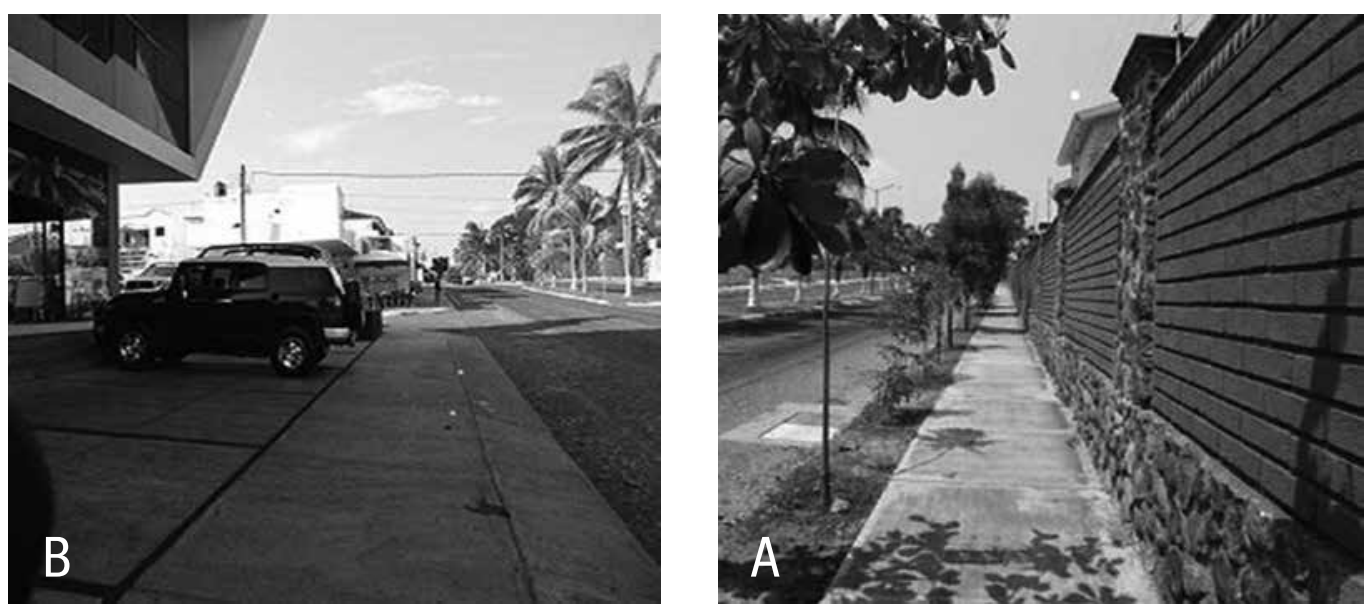

Fuente: Isabel Galaviz 
Figura 4

Calificación relativa a la seguridad

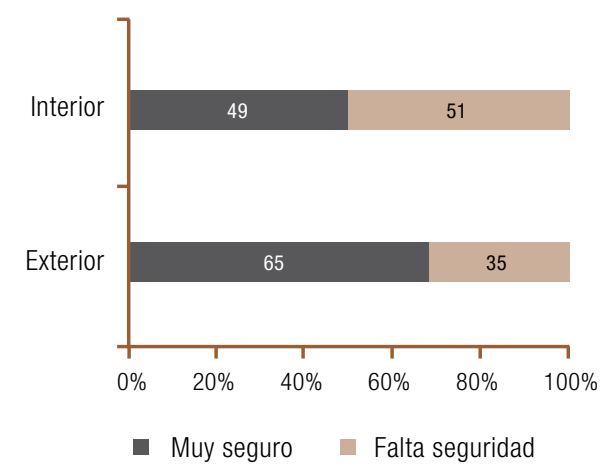

Fuente: elaboración propia

En cuanto a las cualidades espaciales ofertadas en estos fraccionamientos cerrados, se encontró que de un 49 a $80 \%$ de sus moradores califican los aspectos relacionados con la seguridad y protección, respectivamente, en el rango de mala a muy mala y en el rango de buenos a muy buenos los aspectos de tranquilidad, belleza y calidad del espacio público, con 86, 94 y 99\% respectivamente.

Todas las cualidades del fraccionamiento abierto residencial fueron ubicadas en el rango de buenas a muy buenas; un $85 \%$ de los residentes opinó así respecto a la seguridad y protección, $100 \%$ en relación con tranquilidad y belleza y $78 \%$ frente a la calidad del espacio público (Figura 5).
De las calificaciones de sus diferentes contextos inmediatos como su casa, fraccionamiento y ciudad, referidas a su concepción (símbolo y significado) de la inseguridad, se encontró que 45 y $48 \%$ de los habitantes del exterior perciben poca inseguridad en su casa y su fraccionamiento respectivamente y $56 \%$ considera a su ciudad muy insegura, a diferencia de 48 y $50 \%$ de los residentes del interior, quienes califican a su casa y fraccionamiento respectivamente con mucha inseguridad y $57 \%$ como ciudad demasiado insegura (Figura 6).

Figura 6.

Calificaciones en entornos diversos
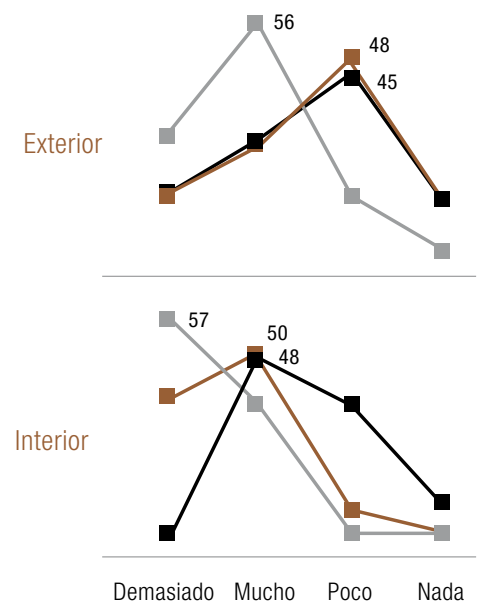

- La ciudad Su fraccionamiento

Su casa

Fuente: elaboración propia

Figura 5.

Calificaciones urbanas

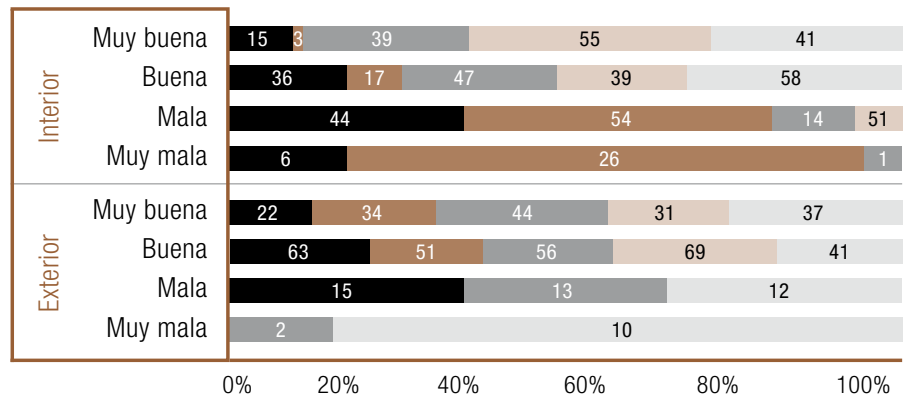

- Seguridad

- Protección

- Tranquilidad

Belleza

Calidad del espacio público (calles, jardines, etc.) 
Para identificar las características físicas que, desde la opinión de los moradores, hacen más seguros a sus fraccionamientos en relación con el resto de la ciudad, se encontró que tanto para los moradores del interior como para los del exterior predominó la ubicación en una buena zona como el elemento que proporciona mayor seguridad (Figura 7).

Figura 7 .

Elementos que otorgan seguridad al fraccionamiento

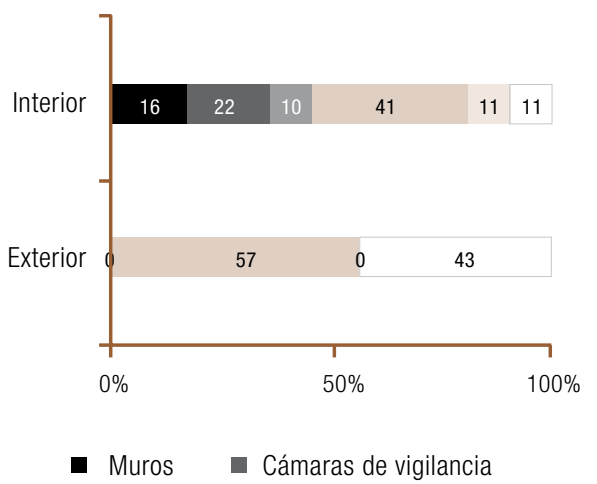

- Control del acceso Ubicado en buena zona

Fuente: elaboración propia

Aunque este dato no fue determinante, permitió inferir que los elementos de cierre, dispositivos de seguridad y controles de acceso de los fraccionamientos cerrados residenciales están más vinculados a los discursos de inseguridad, que a su sensación de seguridad.
Según Hiernaux (2007) y Armando Silva (2008), significar a la ciudad como una imagen articulada con las imágenes apreciadas rutinariamente, acumuladas y evocadas de acuerdo con el estímulo asociado con las características del espacio más cotidiano, son condiciones que causan efectos en la percepción del individuo. Por ello se indagó la frecuencia de uso de espacios abiertos y cerrados. Se encontró que un 54\% de los habitantes del interior utilizan a diario espacios cerrados, a diferencia de los residentes del exterior, en donde solo $22 \%$ los frecuenta cada día (Figura 8).

Ahora bien, las imágenes frecuentes que se almacenan en la memoria y la psique del individuo, aunadas a la predilección del espacio definido por el juicio de valor o significado que cada individuo otorga de acuerdo con sus imaginarios producen sensaciones de afinidad, que son reflejadas en la elección de los espacios para realizar sus rutinas, lo que influirá en los comportamientos urbanos (Beck, 2003; Vuanello, 2006; Hiernaux 2007; Silva 2008; Cisneros, 2008). Encontramos que un $60 \%$ de los residentes del interior prefiere los espacios cerrados y privados. Se observaron datos polarizados, tendientes a una lógica dicotómica interior/exterior, inclusión/exclusión. Los moradores del exterior arrojaron resultados diferidos en los cuatro tipos de espacios y, por tanto, más heterogéneos con tendencia al uso de los espacios privados, pero un $52 \%$ prefiere los espacios abiertos (Figura 9).

Figura 8.

Frecuencia de uso de los espacios

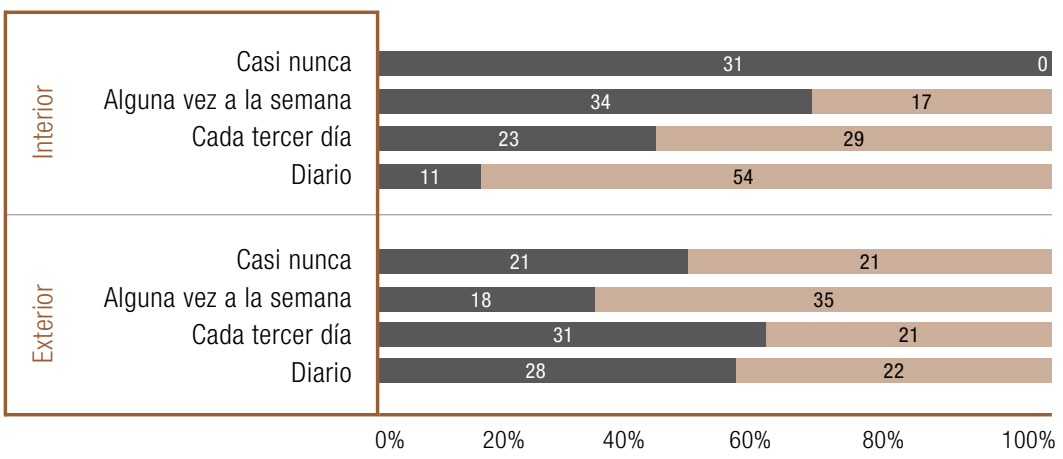

- El aire libre o espacios abiertos

- (porcentaje) En centros comerciales o espacios cerrados (porcentaje) 
Para identificar si los elementos de cierre de los fraccionamientos simbolizan o significan seguridad para sus habitantes, se cuestionó sobre las razones de su predilección por el uso de ciertos espacios (abiertos o cerrados). Para un 52\% de los residentes del interior, la razón para usar con mayor frecuencia los espacios cerrados sí es la seguridad, a diferencia de los moradores del exterior: $42 \%$ por afinidad; $31 \%$, la comodidad; $15 \%$, la cercanía y $12 \%$, la seguridad (Figura 10).

Asimismo, se les pidió ponderar los satisfactores de su necesidad de seguridad. Asignaron una calificación a cinco aspectos de su fraccionamiento, del más al menos importante. Dos de estos aspectos se referían a elementos de cierre y dispositivos de seguridad y el resto, a la calidad espacial y al estado de conservación de los espacios.

Figura 9.

Predilección de uso de los espacios

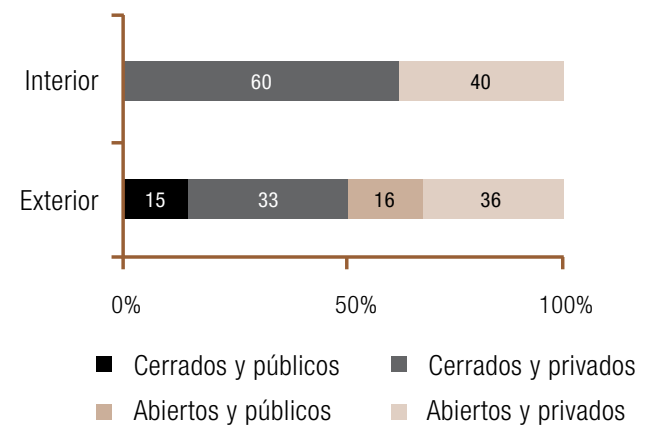

La totalidad de los encuestados del interior ponderaron en primero y segundo lugar la necesidad de aumentar los dispositivos de seguridad en las viviendas y un $94 \%$ en el fraccionamiento. Dejaron los aspectos de calidad y conservación del espacio físico en el resto de los sitios.

Un 64\% de los encuestados del exterior ponderaron en primer y segundo lugar de importancia los aspectos relacionados con la calidad y el mantenimiento del espacio público como elementos necesarios para aumentar su sensación de seguridad y, en el resto de los sitios, la necesidad de aumentar elementos de cierre o dispositivos de seguridad (Figura 11).

Los datos antes cuantificados se codificaron y se analizaron con el software estadístico SPSS. Se definieron tres percentiles para obtener tres

Figura 10.

Razones de predilecciones de uso

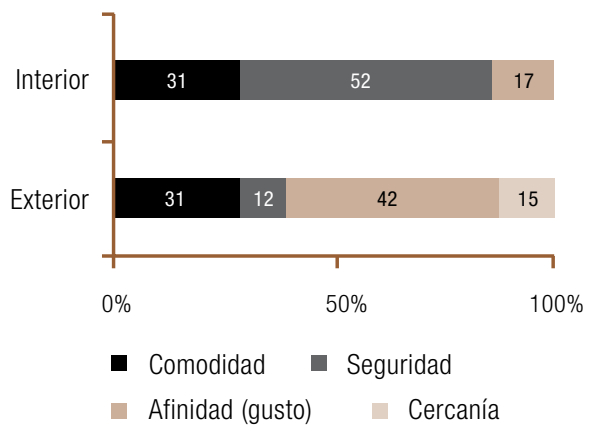

Fuente: elaboración propia

Fuente: elaboración propia

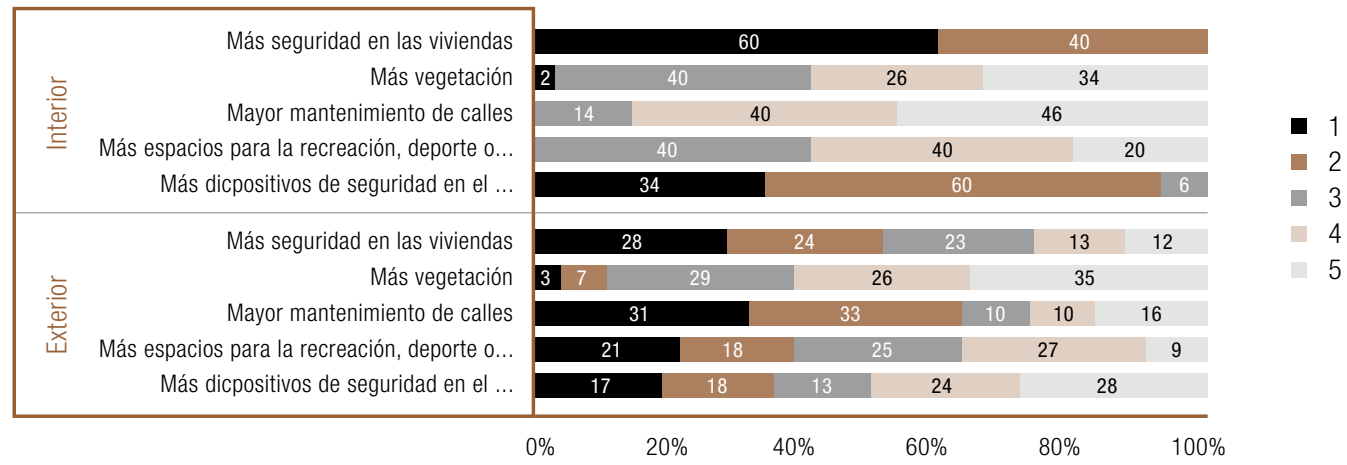


rangos de las variables, que significaron el grado de percepción de riesgo y sentimientos de inseguridad bajo (1), medio (2) y alto (3).

En el caso de la percepción de riesgo, el instrumento contempló 25 preguntas o reactivos. Cada uno de ellos fue codificado con un puntaje mínimo de 1 y máximo de 4 de menor a mayor riesgo, por lo que las puntuaciones oscilaron entre 25 y 92, con una media de 65,27. Los tres percentiles obtenidos fueron de 25 a 57 para el rango de percepción de riesgo bajo, de 58 a 77 para medio y de 78 a 92 para alto.

En cuanto a los sentimientos de inseguridad, el instrumento contempló 14 preguntas o reactivos. Cada uno de ellos fue codificado con un puntaje entre 1 y 4 , de menor a mayor sentimiento de inseguridad, por lo que las puntuaciones oscilaron entre 14 mínimo y 56 máximo, con una media de 41,04. Los tres percentiles obtenidos fueron de 14 a 36 para el rango de sentimientos de inseguridad bajo, de 37 a 46 para medio y de 47 a 56 para alto.

Con esto se compararon medias entre los datos obtenidos para los habitantes del interior y los del exterior. En ambas variables, la media para los residentes del interior fue de 2,7: percepción de riesgo y sentimientos de inseguridad de grado medio con tendencia a alto; la media de los moradores del exterior fue de 1,5 para la percepción de riesgo y 1,4 para los sentimientos de inseguridad, es decir, grado medio (Tabla 1 ).

Tabla 1.

Comparativa de medias

\begin{tabular}{cccc} 
& Media & Desviación típica & $\mathrm{N}$ \\
percrintrangos & 2.7143 & .45502 & 70 \\
\hline percrextrang & 1.5000 & .62765 & 100 \\
& Media & Desviación típica & $\mathrm{N}$ \\
sentintrang & 2.7143 & .56831 & 70 \\
\hline sentextrangos & 1.4900 & .54114 & 100 \\
\hline
\end{tabular}

Fuente: elaboración propia con datos obtenidos del SPSS
Se confirmó que existe una relación entre la percepción de riesgo y los sentimientos de inseguridad de los residentes, con las condiciones de encerramiento y aislamiento de los fraccionamientos cerrados residenciales, ya que el grado de percepción de riesgo y sentimientos de inseguridad de los moradores del interior de las unidades de análisis es mayor que el de la población testigo.

Una vez se establecieron estas relaciones cuantitativas se complementó el estudio con un análisis cualitativo interpretativo de las entrevistas y los mapas mentales, con el que se desarrolló una tabla de patrones de respuesta que nos permitió identificar dos tendencias, clasificadas en los grupos A y B.

En el grupo A, los residentes del interior, se identificaron asociaciones contradictorias, ya que, a pesar de que no han sido víctimas de delito, no han tenido conocimiento de que en su fraccionamiento se hubiese cometido alguno y de que sí habían escuchado en los medios masivos de comunicación y por personas conocidas sobre "delitos cometidos fuera de su fraccionamiento, en la ciudad" y de que cuentan con elementos de cierre, dispositivos de seguridad y controles de acceso, siguen sintiéndose vulnerables o intranquilos dentro de su fraccionamiento. Consideran los espacios abiertos como escenarios que los exponen al riesgo por el solo hecho de no contar con elementos físicos de cierre o dispositivos de seguridad, por lo que, para ellos, los centros comerciales son los lugares más seguros de sus ciudades, porque son espacios cerrados y delimitados. Esto demuestra que los habitantes del grupo A desarrollan representaciones en función de imaginar a la ciudad como un espacio extraño y riesgoso. El solo hecho de ser diferente, heterogéneo o desordenado les hace sentir expuestos y susceptibles a ser víctimas del delito, más por la pérdida del control del espacio y del desconocimiento 
del otro, que por el riesgo objetivo de estar en una situación o un lugar de peligro.

Entonces, debido a que sus sentimientos de inseguridad se originan en un imaginario, se minimiza la evaluación y el juicio objetivo de las condiciones físico-espaciales. Por lo tanto, estos elementos seguirán siendo insuficientes e ineficaces para proporcionar una sensación de seguridad en los residentes del interior.

En el grupo B, los moradores del exterior, aunque $74 \%$ de ellos había sido víctima del delito y en su mayoría había escuchado sobre delitos cometidos en su fraccionamiento, lo percibe como una zona tranquila. La representación de su ciudad es de un espacio tanto de riesgos como de beneficios, en donde los primeros están relacionados con el deterioro de los espacios y la calidad urbana, que son aspectos físicos objetivos de los escenarios facilitadores de hechos delictivos.

Para ellos, los espacios más inseguros de la ciudad, sean cerrados o abiertos, están representados por las zonas marginadas y las colonias que históricamente han estado estigmatizadas como productoras de delincuentes e inseguridad.

Asimismo, no establecen una relación directa entre los dispositivos de seguridad y la sensación de protección, debido a que ven que en la ciudad sí han aumentado los delitos, los sucesos delictivos y la movilización policiaca por cuestiones del narcotráfico, por lo que en ocasiones se sienten intranquilos o vulnerables, pero siguen percibiendo a su fraccionamiento como un espacio seguro, por estar ubicado en buena zona.

Podemos decir que esta representación de la ciudad y su percepción de riesgo está más asociada con aspectos objetivos, pues concentran sus gustos y necesidades en hacer eficiente la seguridad de su fraccionamiento en aspectos como el mejoramiento de la calidad y el sostenimiento urbano, conservar los baldíos sin breña y proporcionar una buena iluminación en las calles, mejorar estrategias policiacas de los organismos de seguridad y dotar de mayor vigilancia preventiva en la vía pública, pero sin mencionar la necesidad de cerrar o aislar a su fraccionamiento, puesto que se sienten parte de esa zona de la ciudad.

No obstante, aunque aprecian los riesgos de la ciudad, se sienten tranquilos dentro de su fraccionamiento, su calle o su entorno y no consideran al encerramiento, aislamiento o los dispositivos de seguridad como alternativa de solución a la inseguridad urbana existente.

\section{Conclusiones}

Los fraccionamientos cerrados residenciales de clase alta de la ciudad conurbada de Colima-Villa de Álvarez no han respondido a las necesidades y particularidades locales; más aún, propician que sus habitantes utilicen como dimensión relevante las representaciones simbólicas referentes a las condiciones de encerramiento y aislamiento sociourbano como medidas de protección y resguardo. Los juicios de valor mediante los cuales definen sus gustos, decisiones y predilecciones cuentan con filtros sustentados en imaginarios del miedo, que convierten los sentimientos de inseguridad en un elemento permanente y cotidiano que se incrementa paulatinamente, ya que no depende de una situación objetiva de riesgo.

Las condiciones de encerramiento y aislamiento sociourbano de estos fraccionamientos, entendidas como la situación objetiva del ambiente primario de quienes los habitan, generan una distinción básica de la situación subjetiva de sus residentes, facilitan y predisponen tendencias subyacentes o de origen relativas a la percepción de riesgo que, más allá de la condición estadística del delito que se conoce, influencian el 
pensamiento, al crear una constante incertidumbre como ideología individual.

Este pensamiento, reforzado con la información aprehendida, se convierte en una creencia generalizada y constituyente de un imaginario social que ubica al miedo en la dimensión relevante, por lo que se enfatizan los sentimientos de inseguridad y se margina al pensamiento reflexivo a la dimensión de opacidad (Pintos, 2003).

Desde este discurso, en los moradores expuestos a las condiciones de encerramiento y aislamiento sociourbano se inhibe la demostración sensitiva positiva de su entorno inmediato y se refuerza una ideología disminuida de argumentos racionales o creencias categóricas, dotadas de retóricas escuchadas, divulgadas, aprehendidas y difundidas por medios masivos o informales de comunicación.

Lo que convierte a los fraccionamientos cerrados residenciales de clase alta en una creencia simbólica de sobrevivencia y autoprotección sociourbana que "defiende" a sus habitantes frente a una ciudad hostil, peligrosa y riesgosa - por el solo hecho de ser dinámica, cambiante, caótica y heterogénea- es que la homogeneidad del interior se va delineando como el instrumento que otorga certeza y certidumbre al grupo de iguales.

Sin embargo, en el lenguaje no verbal de los residentes del interior de los fraccionamientos cerrados, el ambiente extramuros se convierte en un símbolo plausible de la percepción de riesgos, propicia efectos en los ámbitos subjetivos y multifactoriales de sus moradores relativos a su identidad, en las referencias interpretativas, en la cultura, etc. (Pintos, 2003, p. 5). Esto facilita el desarrollo de tendencias no deseadas, como la consolidación de imaginarios del miedo, que suponen una situación subjetiva de inseguridad exponencial y perpetúan los sentimientos de inseguridad de los habitantes internos, ya que no responden a una evaluación objetiva de su entorno.

Lo anterior contribuye al incremento de la inseguridad urbana subjetiva de los residentes de los fraccionamientos cerrados residenciales de clase alta, con lo que se comprueba que las condiciones de encerramiento y aislamiento sociourbano de los fraccionamientos cerrados residenciales de clase alta de la ciudad conurbada Colima-Villa de Álvarez, modifica la estructura psicosocial de sus moradores.

Esta condición modifica las rutinas de sus habitantes y sus prácticas urbanas. Convierte a la inseguridad urbana subjetiva en el filtro urbanístico que se expresa territorialmente en la reconfiguración espacial y que, mediante un proceso de ajuste derivado del metabolismo urbano (Burgess, 1995) propio de las ciudades, produce sociedades afectadas en lo psicosocial y urbanístico, que van consolidando colectividades temerosas y una espiral ascendente de inseguridad urbana subjetiva.

Las características físico-espaciales de los fraccionamientos cerrados residenciales contribuyen a que en el filtro de evaluación de sus residentes se ponderen los aspectos subjetivos de su contexto sociourbano y se condicionen a vivir, actuar, pensar, comportarse individualmente y enfrentar una realidad parcializada, que no se sustenta en aspectos de riesgo objetivo. Esto propicia que en el ámbito individual se aumente la percepción de riesgo y los sentimientos de inseguridad y, en el social, los imaginarios del miedo.

Con todo esto se marca una tendencia a la paranoia permanente, que aumentará los muros físicos y fortalecerá los muros sociales, al imprimir la cultura del miedo como el elemento fundamental de la estructuración y producción del espacio sociourbano (Figura 12). 
Figura 12.

Conclusiones

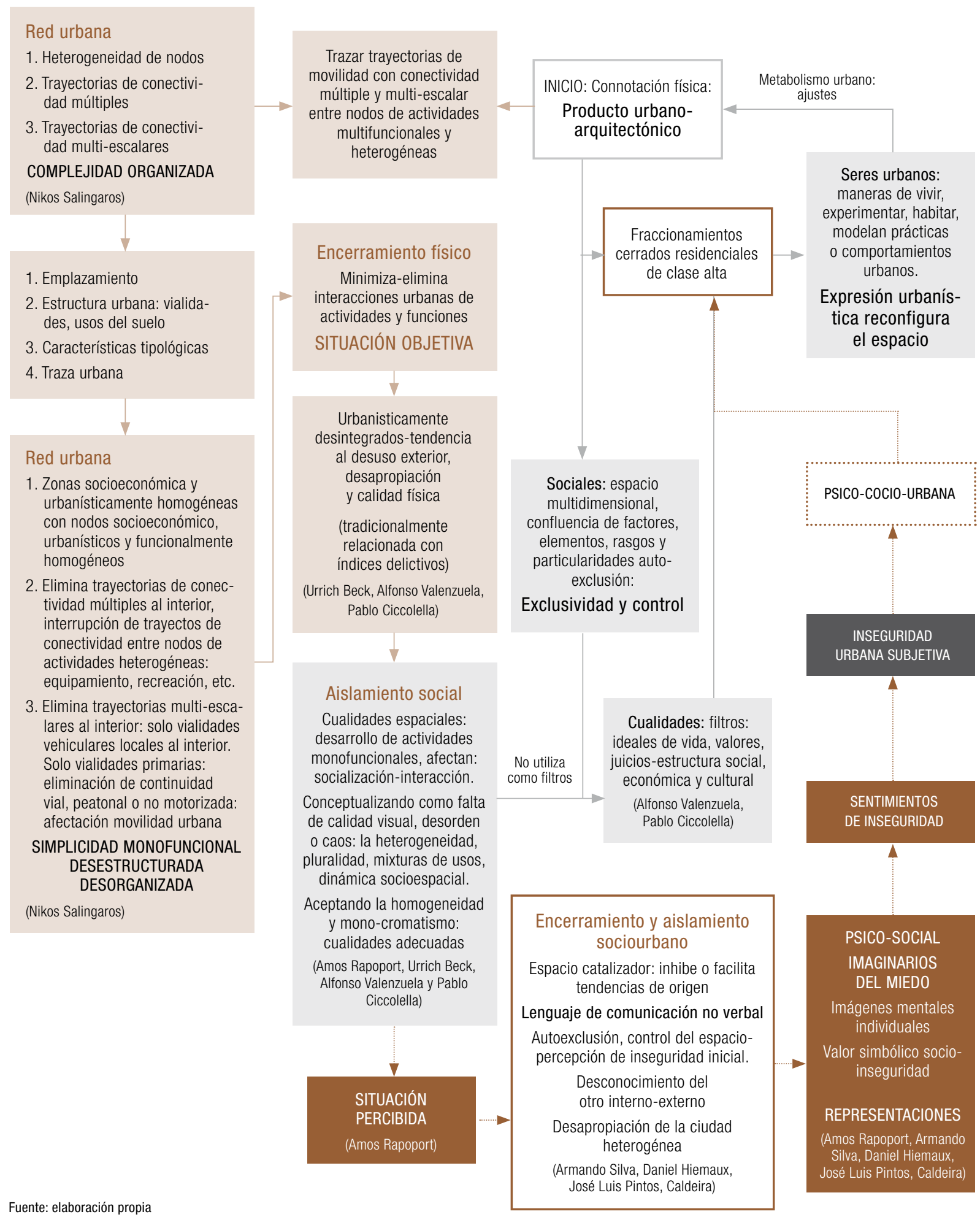




\section{Bibliografía}

Bauman, Z. (2007). El miedo líquido. Madrid: Paidós.

Beltrao, S. (2007). La inseguridad y los espacios residenciales controlados en ciudades medias del estado de Sao Paulo. RNIU, XXX, 1-14.

Burgess, E. (1995). The Growth of the City. Recuperado de http://www.cpjetd.org

Cáceres, G., y Sabatini, F. (2004). Reseña de barrios cerrados en Santiago de Chile: entre la exclusión y la integración residencial. EURE, (30), 114-117.

Cárdenas Munguía, F. J. (2004). Pequeños espacios abiertos de encuentro vecinal, caso Colima-Villa de Álvarez. Colima: Universidad de Colima.

Cisneros, J. L. (2008). La geografía del miedo en la Ciudad de México; el caso de dos colonias de la delegación Cuauhtémoc. El Cotidiano, (152), 59-72.

Chávez, M., Gómez Garcia, E., y Valladares Anguiano, R. (1996). El desarrollo urbano de la zona conurbada Colima-Villa de Álvarez. Sociedad Nueva, 1 (2), 25-35.

Ciccolella, P., y Mignaqui, I. (2008). Metrópolis latinoamericanas: fragilidad del Estado, proyecto hegemónico y demandas ciudadanas. Algunas reflexiones a partir del caso de Buenos Aires. Cendes, 25 (69), 47-68.

Giglia, A. (2003). Espacio público y espacios cerrados en la Ciudad de México (Crisis del espacio público y nueva segregación urbana). México D. F.: Flacso.
Hiernaux, D. (2007). Los imaginarios urbanos: de la teoría y los aterrizajes en los estudios urbanos. EURE, XXXIII (99), 17-30.

Juárez Martínez, M. (2006). Segregación urbana y sus implicaciones en las ciudades, Una aproximación teórica. Palapa, 1 (2), 45-50.

Marcuse, P. (2001). Enclaves Yes, Ghettoes No: Segregation and the State. Recuperado de http:// www.urbancentre.utoronto.ca/pdfs/curp/Marcuse_Segregationandthe.pdf

Maycotte, P. (2006). El dentro y fuera en conjuntos habitacionales en condominio el espacio público: extensión del ámbito privado. Crisol Fusión de Ideas, 1 (1), 83-103.

ONU-Hábitat y Sedesol. (2011). Estado de las ciudades de México 2011. Programa de las Naciones Unidas para los Asentamientos Humanos. México D. F.: Autor.

Paulsen, A. (2010). Reseña de seguridad, temores y paisajes urbanos. Revista de Geografía, Norte Grande, (46), 149-153.

Pintos, J. L. (2003). Los imaginarios sociales del delito. Santiago de Compostela, Buenos Aires. Anthropos, (198), 161-176.

Quintero, C. (2007). La percepción en el espacio calle: parámetros de calidad ambiental caso de estudio: calle 67. Cecilio Acosta, Maracaibo, Venezuela. Espacio Abierto, 16 (4), 815-840.

Rapoport, A. (1978). Aspectos humanos de la forma urbana. Hacia una confrontación de las ciencias sociales con el diseño de la forma urbana. Barcelona: Gustavo Gili.

Sabatini, F. (2008). La segregación, los guettos y la Integración social urbana: mitos y claves. EURE, XXXIV (103), 5-26. 
Salingaros, N. (2005). Teoría de la red urbana. Recuperado de http://zeta.math.utsa.edu/ - yxk833/ urbanweb-spanish.pdf

Silva, A. (2008). Imaginarios urbanos: hacia el desarrollo de un urbanismo desde los ciudadanos. Bogotá: Flacso.

Valenzuela, A. (2007). Santa Fe (México): megaproyectos para una ciudad dividida. Cuadernos Geográficos, 40 (2007-1), 53-66.
Valladares, R. (2006). Estructura urbana y delincuencia. El caso Colima-Villa de Álvarez 19992002. (Tesis doctoral inédita). Universidad de Colima, México.

Vuanello, R. (2006). Un nuevo instrumento de evaluación psicológica: el cuestionario de Inseguridad Urbana (CIU). Interdisciplinaria, 23 (1), $17-45$. 